\title{
A produção de fanzines como recurso para o ensino de leitura e produção de textos: análise de uma experiência com estudantes de cursos técnicos de nível médio
}

Luana de Gusmão Silveira ${ }^{1}$

Marizete Bortolanza Spessatto

\begin{abstract}
Resumo:
O presente artigo tem como objetivo refletir sobre as contribuições do gênero textual fanzine no processo de ensino-aprendizagem da leitura e da escrita. Descrevem-se os resultados de uma experiência desenvolvida com estudantes de cursos técnicos de nível médio de uma instituição da Rede de Educação Profissional, Científica e Tecnológica, localizada no sul do país. As produções textuais em análise foram realizadas durante oficinas vinculadas à disciplina de Língua Portuguesa e Literatura e entrelaçadas à temática da Semana Nacional de Ciência e Tecnologia de 2019. Além dos fanzines produzidos pelos alunos, apresenta-se a avaliação da experiência pelos próprios estudantes, por meio da análise de questionários com questões abertas e fechadas, aplicados aos participantes da proposta. Como base teórica, tomam-se como referência as produções sobre leitura e escrita na escola e sobre os fanzines como recursos para assegurar o protagonismo dos estudantes. Os resultados apontam que esse gênero se caracteriza como uma ferramenta significativa na formação do sujeito leitor-escritor. Ainda, revelam a possibilidade de inserir a leitura e a escrita em contextos reais de comunicação, de modo a fazer sentido para os estudantes/leitores e produtores de textos, ao mesmo tempo em que efetiva, na escola, o tripé ensino, pesquisa e extensão.
\end{abstract}

\author{
Palavras-chave: \\ Produção escrita. Leitura. Fanzine.
}

\footnotetext{
1 Mestre em Linguística. Instituto Federal de Educação, Ciência e Tecnologia de Santa Catarina, Garopaba, Santa Catarina, Brasil. E-mail: luana.gusmao@ifsc.edu.br. ORCID iD: https://orcid.org/0000-0003-2160-5327.

2 Doutora em Educação. Instituto Federal de Educação, Ciência e Tecnologia de Santa Catarina, Florianópolis, Santa Catarina, Brasil. E-mail: marizete.spessatto@ifsc.edu.br. ORCID iD: https://orcid.org/0000-0003-0213-833X.
} 


\title{
The making of fanzines as a resource for teaching reading and text production: analysis of an experience with high school technical course students
}

\begin{abstract}
:
This article aims to reflect on the contributions of the textual genre fanzine in the teaching-learning process of reading and writing. The results of an experience developed with students of medium-level technical courses from an institution of the Rede de Educação Profissional, Científica e Tecnológica, located in the South of the country, are described. The textual productions under analysis were carried out during workshops linked to the Língua Portuguesa e Literatura subject and intertwined with the theme of the 2019 Semana Nacional de Ciência e Tecnologia. This article presents the experience evaluation by the students themselves, through the analysis of questionnaires with open and closed questions, applied to the proposal participants. As a theoretical basis, we take as a reference the productions about reading and writing at school and about fanzines as resources to ensure the role of students in these activities. The results show that this genre is characterised as a significant tool in the formation of the reader-writer subject. Still, the experience reveals the possibility of inserting reading and writing in real communication contexts, in order to make sense to students/readers and text producers, while effectuating, at school, the teaching, researching and extension tripod.
\end{abstract}

\section{Keywords:}

Writing production. Reading. Fanzine.

\section{La producción de fanzines como recurso para la enseñanza de la lectura y la producción de textos: análisis de una experiencia con estudiantes de cursos técnicos de secundaria}

\section{Resumen:}

Este artículo objetiva la reflexión acerca de los aportes del género textual fanzine en el proceso de enseñanza-aprendizaje de la lectura y la escritura. Son descriptos los resultados de una experiencia desarrollada con estudiantes de los cursos técnicos de la enseñanza secundaria de una institución de la Rede de Educação Profissional, Científica e Tecnológica, ubicada en el Sur del país. Las producciones textuales en análisis fueron realizadas durante talleres vinculados a la asignatura de Língua Portuguesa e Literatura e interconectada a la temática de la Semana Nacional de Ciência e Tecnologia de 2019. Como base teórica, tomamos como referencia las producciones sobre lectura y escritura en la escuela y sobre fanzines como recursos para asegurar el papel de los estudiantes en estas actividades. Los resultados apuntan que ese género se caracteriza como una herramienta significativa en la formación del sujeto lector-escritor. Aún así, revelan la posibilidad de insertar la lectura y la escritura en contextos reales de comunicación, con el fin de dar sentido a los estudiantes/lectores y productores de textos, y a la vez efectiva, en la escuela, el trípode enseñanza, investigación y extensión.

Palabras clave:

Producción escrita. Lectura. Fanzine. 


\section{Introdução}

Tendo em vista uma evidente resistência por parte dos adolescentes em atuarem de forma efetiva em propostas que envolvam a leitura e a produção textual na escola, faz-se necessário investir no planejamento e na elaboração de práticas pedagógicas que ressignifiquem essas ações. A bem da verdade, lidar com essa resistência dos jovens a atividades que envolvam a leitura e a escrita requer repensar a forma como essas questões têm sido trabalhadas em sala de aula, na transição entre a infância (anos iniciais) e a adolescência (anos finais do ensino fundamental e ensino médio). Ceccantini (2009) afirma haver, nessa fase da escolarização, uma ruptura na proposta de formação do leitor literário. Em outras palavras, quanto maior a idade, menor é o grau de leitura entre os estudantes brasileiros. ${ }^{3}$ Diante dessa realidade, os professores são desafiados, diariamente, a encontrar novas maneiras de proporcionar a ampliação dos conhecimentos de leitura e escrita por meio de atividades que sejam significativas e capazes de envolver os estudantes, sobretudo, os jovens ligados ao ensino médio. Metodologias diferenciadas, principalmente as que colocam os estudantes como protagonistas no trabalho com a leitura e a escrita, alinhadas com a diversidade de gêneros textuais, podem se constituir em atrativos para esses jovens estudantes. Como defendemos, neste trabalho, a proposição de novos gêneros na escrita em sala de aula, como os fanzines $^{4}$, é interessante, como podemos ver na definição apresentada por Marcuschi a respeito do tema. De acordo com o autor:

Usamos a expressão gênero textual como uma noção propositalmente vaga para referir os textos materializados que encontramos em nossa vida diária e que apresentam características sociocomunicativas definidas por conteúdos, propriedades funcionais, estilo e composição característica. Se os tipos textuais são apenas meia dúzia, os gêneros são inúmeros. Alguns exemplos de gêneros textuais seriam: telefonema, sermão, carta comercial, carta pessoal, romance, bilhete, reportagem, aula expositiva, reunião de condomínio, notícia jornalística, horóscopo, receita, bula de remédio, lista de compras, cardápio de restaurante, instruções de uso, outdoor, inquérito policial, resenha, edital de concursos, piada, conversa espontânea, conferência, carta eletrônica, bate-papo por computador, aulas virtuais e assim por diante (MARCUSCHI, 2010, p. 23).

É muito comum, no decorrer das aulas, observar manifestações dos adolescentes como: "ah, eu não gosto de ler"; "Ler é muito cansativo"; ou, ainda, a afirmação de que "não sei escrever" ou de que "não quero escrever porque é chato". Tal situação está muito relacionada ao fato de que o trabalho de leitura e produção textual acaba se restringindo muito aos gêneros pertencentes ao universo escolar, como: resenha, relatório, resumos, redação etc., desvinculando a prática de leitura e escrita das práticas sociais que permeiam o universo adolescente.

É sabido que desenvolver um ensino desvinculado das questões relacionadas ao cotidiano dos alunos faz com que o processo de ensino-aprendizagem seja visto como "sem sentido". A esse

\footnotetext{
3 Há, também, um declínio na influência dos professores quanto aos hábitos de leitura, à medida que os estudantes avançam nos anos de escolarização, como mostram os dados da pesquisa Retratos da Leitura no Brasil. Na edição de 2016, as "dicas de professores" aparecem como mais influentes na aquisição de hábitos de leitura para os alunos entre cinco e dez anos de idade. Apenas $12 \%$ dos alunos entrevistados na faixa dos quatorze aos dezessete anos consideraram significativa a influência do professor (CECCANTINI, 2016, p. 94). 4 Num exame etimológico da palavra, fanzine vem de fanatic magazine, que, literalmente, significa "revista de fã" (MAGALHÃES, 1993). Para um maior detalhamento a respeito do histórico dos fanzines, sugere-se a leitura dos títulos publicados por Henrique Magalhães, Edgar Guimarães e Márcio Sno. Entendemos os fanzines como um gênero textual (ZAVAM, 2006). A autora parte da diferenciação feita por Marcuschi (2003) entre gênero e suporte, afirmando que: "De acordo com essa definição, poderíamos, então, tomar o fanzine como gênero textual, posto que tanto se trata de um texto com 'padrões sociocomunicativos característicos definidos por sua composição, objetivos enunciativos e estilo', quanto pode estar incluído na listagem aberta, assinalada pela expressão 'e assim por diante'" (ZAVAM, 2006, p. 12).
} 
respeito, vale retomar as orientações dos Parâmetros Curriculares Nacionais (BRASIL, 2006), no que concerne ao ensino da Língua Portuguesa, pois, de acordo com o documento:

Se, na sala de aula, o estudante analisa textos com os quais convive fora da escola, as relações que faz entre os conteúdos disciplinares e sua vivência tornam-se muito mais significativas. Não se pode relevar a importância de suportes diversos do livro - cuja leitura é tão cobrada nas aulas de literatura - e se estendem à revista, ao jornal, à enciclopédia, ao outdoor, para citar apenas alguns. Somente como leitores de múltiplos textos os alunos desenvolverão a contento sua competência textual. (BRASIL, 2006, p. 75).

Foi, portanto, com o intuito de fomentar o desenvolvimento da competência textual e de valorizar a cultura trazida pelos jovens para o ambiente escolar, revelando ao estudante que a prática de leitura e produção de textos pode e deve ser envolvente, criativa, divertida, lúdica ou, ainda, nas palavras dos próprios adolescentes, "super maneira", que surgiu a proposta de executar, no planejamento das aulas de Língua Portuguesa e Literatura II, as oficinas de leitura e produção de fanzines. Posteriormente, elas culminaram em projetos de pesquisa e extensão. É por esse tripé que seguimos, na próxima seção.

\section{Descrição da prática: entrelaçando ensino, pesquisa e extensão com a leitura e a produção de textos}

Se partimos do princípio, como já apresentado, de que a leitura e a produção de textos na escola precisam articular os gêneros textuais presentes no cotidiano dos jovens, por outro lado, também, não podemos pensar a produção de conhecimentos na escola sem considerar o tripé ensino, pesquisa e extensão. No Plano de Desenvolvimento Institucional-PDI do Instituto Federal de Educação, Ciência e Tecnologia de Santa Catarina-IFSC, instituição na qual as atividades aqui descritas foram desenvolvidas, destaca-se a necessidade de manutenção desse tripé, de modo a assegurar a educação integral do sujeito (IFSC, 2015). No documento que orienta as práticas educativas institucionais, a articulação entre ensino, pesquisa e extensão é descrita considerando-se que,

[...] no ensino, inter-relacionam-se os diferentes saberes; na pesquisa, eleva-se o conhecimento a novos patamares do saber e; na extensão, compartilham-se conhecimentos com a sociedade, contribuindo dessa forma para o cumprimento da missão institucional. (IFSC, 2015, p. 10).

A instituição em análise conta com 22 campi, distribuídos geograficamente em todas as regiões de Santa Catarina. A ação aqui foi desenvolvida no campus Garopaba. O município, com registros de povoamentos portugueses datados de 1530, fica localizado na região sul do Estado, a pouco mais de setenta quilômetros de Florianópolis. O projeto de ensino foi desenvolvido na disciplina de Língua Portuguesa e Literatura II, com aproximadamente sessenta alunos vinculados aos cursos técnicos integrados ${ }^{5}$ ao ensino médio, de Administração e de Informática. A proposta foi efetuada em diferentes etapas, ao longo das quais foram sendo construídos, com criticidade e criatividade, os fanzines.

Inicialmente, foi feita a apresentação do projeto aos alunos das duas turmas e contextualização a respeito do que é fanzine, incluindo a exibição e discussão do documentário Impressão

5 Curso técnico integrado, também chamado de ensino médio técnico, oferece a formação geral de forma integrada à formação profissional. O aluno tem as disciplinas do currículo normal do ensino médio e as específicas do curso técnico escolhido. Já, nos cursos técnicos concomitantes, o aluno faz as disciplinas do currículo normal do ensino médio em uma escola da sua preferência e as disciplinas do curso técnico no Instituto Federal. E, por último, destacam-se os cursos técnicos subsequentes, que oferecem uma formação técnica aos alunos que já concluíram o Ensino Médio. 
Minha ${ }^{6}$. Em seguida, partiu-se para o levantamento de subtemas relacionados à temática da Semana Nacional de Ciência e Tecnologia (SNCT): Bioeconomia - diversidade e riqueza para o desenvolvimento sustentável. Feito isso, procedeu-se à exploração de resenhas relacionadas aos temas escolhidos, de modo a assegurar a ampliação do repertório dos alunos acerca da temática.

Como produção de fanzines, demanda o conhecimento de técnicas de diagramação, em outra das etapas do trabalho, os alunos foram orientados à pesquisa de elementos de estilo, técnicas ilustrativas e, por fim, a produção de um boneco/projeto, utilizando uma folha A4, explorando a estrutura básica do fanzine. Por último, os estudantes participaram de uma oficina de arte, com o objetivo de conhecer diferentes técnicas como: xilogravura, gravura em metal, estêncil, carimbos e trabalhos com colagens. Feito esse percurso, foi possível a construção dos fanzines, exposição e comercialização ${ }^{7}$ na Semana Nacional de Ciência e Tecnologia de 2019.

Sendo o fanzine, conforme afirma Magalhães (1993, p. 09-10), “[...] uma publicação alternativa e amadora, geralmente de pequena tiragem e impressa artesanalmente [...]", as etapas de produção descritas anteriormente foram seguidas de modo a possibilitar autonomia na produção, por parte dos estudantes envolvidos, utilizando, dessa forma, uma das características mais importantes desse tipo de produção, que é a participação dos autores em todo o processo, "[...] desde a concepção da ideia até a coleta de informações, diagramação, composição, ilustração, montagem, paginação, divulgação, distribuição e venda" (MAGALHÃES, 1993, p. 09-10).

Nota-se que os jovens leitores-escritores, ao produzirem seus fanzines, desempenharam várias funções até alcançar o resultado final. No caso aqui em análise, durante o percurso, tiveram a oportunidade de estabelecer contato com gêneros textuais de outras esferas que viriam a compor os seus fanzines: poemas, músicas, tirinhas, charge, propagandas etc. Vale citar, ainda, o planejamento relativo à elaboração das páginas, pois os jovens-autores tiveram de se valer de diferentes técnicas como o uso de colagens de fotografias, de jornais, revistas, desenhos, gravuras, xérox, bordado, costura em papel e textos escritos manualmente ou à máquina de escrever. ${ }^{8}$

Observa-se que fazer um fanzine é apropriar-se de diferentes manifestações artísticas e também de múltiplos gêneros textuais; trata-se de um processo em que a criatividade se faz presente em todas as etapas. A esse respeito, destaca-se a reflexão de Neto e Andraus (2010) no que concerne ao trabalho com fanzines em sala de aula. De acordo com os autores, além das possibilidades interativas e interdisciplinares, esses textos também proporcionam aos alunos um "[...] rico processo psíquico que se dá ao colocarem as 'mãos na massa', já que o trabalho também pede bastante intervenção manual” (NETO; ANDRAUS, 2010, p. 41).

A título de ilustração, destaca-se o fanzine produzido por um dos alunos participantes do projeto. O título da proposta é Natureza sem cor e a produção foi desenvolvida em formato de uma folha de árvore. Ainda em relação à "intervenção manual", vale observar a réplica de uma folha confeccionada com tecido e bordada à mão. O mesmo fanzine ainda apresenta uma semente de girassol acompanhada pelos seguintes dizeres: plante, cuide, viva, respeite, chamando a atenção do leitor para a importância da preservação da natureza. Nota-se o entrelaçamento com recursos tecnológicos, ${ }^{9}$ a partir da utilização dos $Q R$ Codes, que permitem uma interação maior com o conteúdo, levando o leitor a outras produções que possam vir a complementar a temática abordada.

\footnotetext{
60 documentário Impressão Minha apresenta um recorte da cena de livros e publicações independentes, em São Paulo e no Brasil. Entre artistas, editores e seus livros, o documentário abre espaço para reflexões sobre mercado editorial, a oposição entre digital e impresso, o livro como objeto, as técnicas artísticas e de impressão. Disponível em: http://impressaominha.com.br/. Acesso em: 30 set. 2021. 7 É relevante destacar que os recursos adquiridos com a comercialização dos fanzines foram direcionados para a "caixinha" de formatura das turmas participantes do projeto.

8 Foi disponibilizada, aos estudantes, uma máquina de escrever, de modo a propiciar a experiência da produção de textos a partir de um dispositivo que os jovens não estão familiarizados, pois difere dos computadores e celulares.

9 Se, em sua concepção inicial, os fanzines eram reproduzidos em mimeógrafos ou fotocopiadoras, hoje, com o avanço da tecnologia, é possível encontrar versões como e-zines ou, ainda, eletronics magazines, ou, como vimos no exemplo, a junção do trabalho artesanal, com referência ao avanço tecnológico.
} 
Figura 1: Página do fanzine "Natureza sem cor"

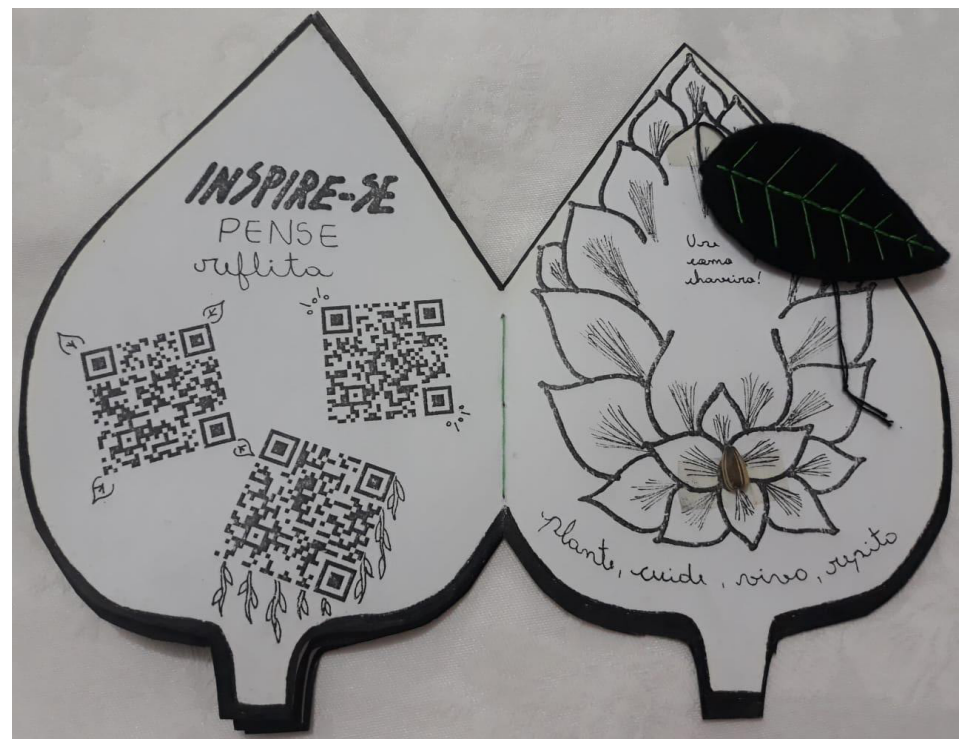

Fonte: Arquivo pessoal das autoras.

Como já ressaltado, o tema estabelecido para leitura, análise, pesquisa e confecção dos fanzines esteve ligado à temática da SNCT de 2019: Bioeconomia: diversidade e riqueza para o desenvolvimento sustentável. A partir da temática, os alunos puderam desmembrar subtemas ligados à bioeconomia para concretizar a confecção. As subtemáticas foram bem diversificadas, no entanto, as que mais se destacaram foram: sustentabilidade ambiental, fome, segurança alimentar, conceituação de bioeconomia, energia verde, lixo, biocombustíveis, agrotóxicos, entre outros. $\mathrm{Na}$ Figura 2, apresenta-se uma parte do conjunto das produções realizadas no decorrer do projeto:

Figura 2: Capas de Fanzines produzidos no projeto

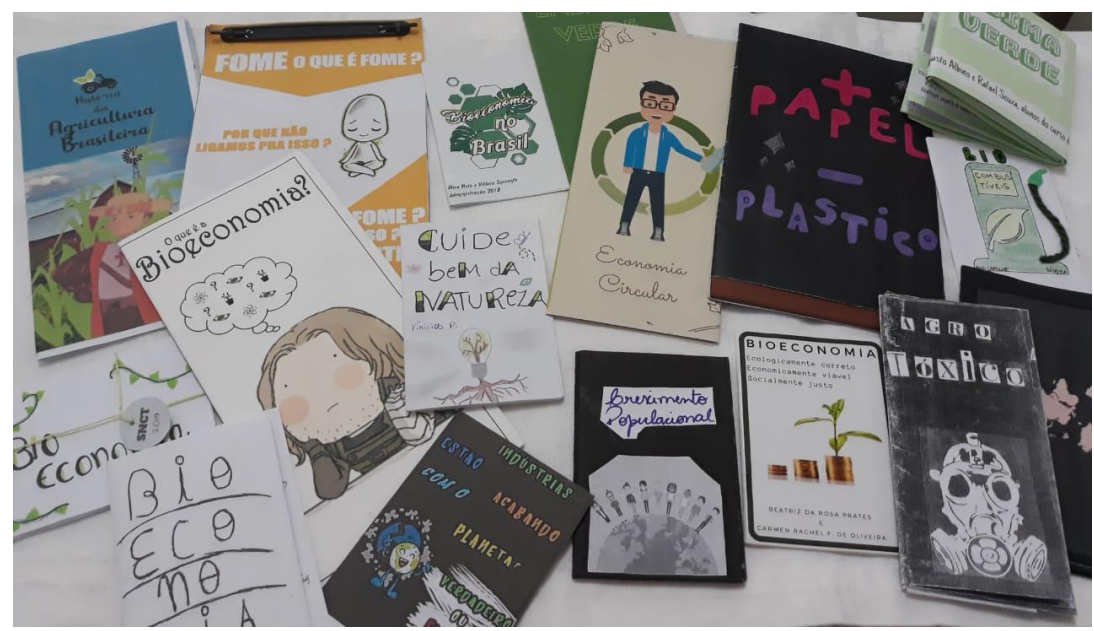

Fonte: Arquivo pessoal das autoras.

No que concerne ao processo avaliativo inerente ao projeto de ensino, destaca-se que a avaliação contemplou as seguintes etapas: 1) proposta original; 2) criatividade; 3) adequação ao tema proposto; 4) aspectos de diagramação e técnicas artísticas; 5) argumentação/criticidade (percepção a respeito da temática proposta). O estabelecimento de critérios possibilitou aos estudantes a clareza quanto ao que estava sendo exigido. 
Alinhado às atividades de ensino desenvolvidas junto aos estudantes, propôs-se o projeto de pesquisa intitulado "Fanzinando ideias: a produção de fanzines como recurso pedagógico no ensino da leitura e produção de textos" ${ }^{10} \mathrm{O}$ objetivo foi analisar os efeitos gerados pela prática de produção de fanzines, por meio do projeto de ensino, no processo de ensino-aprendizagem da leitura e da escrita. Nossa abordagem toma, especialmente, as reflexões de Angela Kleiman (1993) acerca da relação entre texto, leitura, linguagem e aprendizagem, nas práticas de sala de aula. Discutimos e analisamos esses conceitos a partir das propostas apresentadas pela autora, segundo a qual a leitura e a produção textual devem ter reservado lugar de destaque não apenas para os professores de Língua Portuguesa, mas para os demais professores.

É preciso que se considere, nas discussões sobre as práticas de trabalho com texto em sala de aula, tanto em atividades de leitura quanto de escrita, aspectos sócio-históricos e culturais. As formas como os textos são apresentados aos alunos devem levar em conta, sobretudo, as realidades socioculturais em que se inserem, a faixa etária e, ainda, os conjuntos de interesses que fazem parte do seu cotidiano. A premissa é de que todo processo de aquisição da escrita precisa ser produzido de forma concreta, a partir do vivido. Por isso, as atividades e os recursos pedagógicos utilizados no ensino da língua materna precisam ir além do conhecimento das regras gramaticais, revelando ao discente que a língua é muito mais do que um sistema de regras, a língua é dialógica e produz efeitos a partir do contexto em que é produzida.

Comprova-se, assim, a necessidade de implementação de recursos e práticas pedagógicas capazes de fomentar os processos de leitura e produção textual, em uma perspectiva significativa para os estudantes. Com o intuito de contribuir para com essa proposta é que surgiu a investigação, aqui explanada, a respeito dos efeitos alcançados com a produção de fanzines, no que concerne ao trabalho com a leitura e a produção de textos em sala de aula. Para isso, tomou-se como corpus de análise os relatos produzidos pelos alunos, ao final de cada oficina desenvolvida nas atividades pedagógicas em sala de aula, aqui já descritas. Também foram aplicados questionários aos sessenta estudantes participantes das atividades, contendo questões abertas e fechadas, com o intuito de observar de que forma as experiências adquiridas ao longo do processo contribuíram ou não para a prática de leitura e produção textual.

Sabe-se que a produção de fanzines preza, sobretudo, pela liberdade de criação e expressão. Livre de censura, os jovens estudantes tiveram liberdade de expressão autoral, espaço para a exposição de argumentos e de criticidade sobre as questões relacionadas à temática da Semana Nacional de Ciência e Tecnologia, conforme proposto nas oficinas. Nota-se que, dessa forma, passam a exercer um papel ativo no desenvolvimento das atividades, pois na produção de fanzines "[...] a experimentação da prática de autoria encontra acolhimento, elegendo o aluno à categoria daquele que sabe e pode informar" (MARANHÃO, 2012, p. 107). Ainda de acordo com a autora, é preciso considerar que:

De início, tem-se o fato óbvio de que, por meio dos zines, há a inversão da visibilidade de quem fala e de quem deve ser ouvido. [...] O aluno, quando muito consumidor de textos curtos (ou de textos de livros paradidáticos a serem trabalhados por meio de fichas de leitura), passa a ser autor, assumindo o papel daquele que se mostra aos outros, sendo capaz de informar e não apenas receber informações. (MARANHÃO, 2012, p. 58-59).

Desse modo, os alunos participantes da proposta tiveram um espaço real de criação autoral, no qual puderam materializar diferentes manifestações de linguagem, revelando suas visões de mundo, seus argumentos, seus posicionamentos. Zilberman (2012), ao refletir sobre os desafios da

10 O Projeto "Fanzinando ideias: a produção de fanzines como recurso pedagógico no ensino da leitura e produção de textos" foi apoiado com recursos do Edital n. 01/2019/PROPPI - Programa de Iniciação Científica Júnior (PIBIC-EM). 
sala de aula, mais especificamente ao ensino da leitura e da escrita, declara que: "Se a escrita não é a única expressão da linguagem, é a mais prestigiada, a qual todos precisam ter trânsito livre, desembaraçado de preconceitos e dificuldades". Ainda nas palavras da autora, destaca-se o fato de que "[...] privar o indivíduo dessa relação com o universo da leitura e da escrita é formar um cidadão pela metade ou nem formá-lo" (ZILBERMAN, 2012, p. 212).

Em suma, acredita-se que as oficinas proporcionaram uma forma de valorizar a bagagem cultural trazida pelo aluno para o ambiente escolar, promovendo a criatividade e a prática da leitura e da escrita, por meio do entrelaçamento de saberes. Por isso, é primordial, em nosso entendimento, pesquisar, observar e sistematizar os efeitos produzidos no decorrer deste processo, fazendo uso desses resultados para repensar as práticas cotidianas em sala de aula, respeitando as vozes dos sujeitos do processo ensino-aprendizagem.

No início desta seção, destacou-se que a experiência aqui em análise promoveu o tripé ensino, pesquisa e extensão. Antes de passarmos à reflexão dos resultados da proposta da pesquisa anteriormente descrita, explanaremos a respeito das atividades extensionistas que caracterizam essa prática. A resolução do Conselho Superior do IFSC-CONSUP, de n ${ }^{\circ} 61$, de doze de dezembro de 2016, tem como propósito regulamentar essas atividades. Em seu artigo primeiro, ao conceituar a extensão, declara que ela é: "[...] entendida como um processo educativo, cultural, político, social, científico e tecnológico que promove a interação dialógica e transformadora entre o IFSC e a sociedade de forma indissociável ao ensino e à pesquisa" (IFSC, 2016, p. 02).

Em consonância com esse pressuposto, os alunos desenvolveram dois eventos de extensão, um intitulado Vamos fanzinar? Oficina de criação de zines ${ }^{11}$ e outro que contemplou uma "Exposição de Fanzines". A mbos objetivaram promover a divulgação, junto à comunidade externa, participante ativa das atividades relacionadas à Semana Nacional de Ciência e Tecnologia, dos conhecimentos produzidos e desenvolvidos nos projetos de ensino e pesquisa mencionados nos tópicos anteriores, proporcionando, desse modo, a interação dialógica entre a sociedade, os servidores e os discentes do Instituto Federal de Santa Catarina.

\section{Da escola para a sociedade: as ações de ensino, pesquisa e extensão e a avaliação dos estudantes}

Alguns resultados podem ser apontados a partir da observação do desenvolvimento das oficinas (projeto de ensino, realizado de maio a outubro de 2019), bem como das questões apontadas nos questionários aplicados junto aos estudantes (projeto de pesquisa, concluído em novembro de 2019). Nota-se que as atividades de extensão, realizadas de forma atrelada à programação da Semana Nacional de Ciência e Tecnologia, executada no período de 21 a 25 de outubro de 2019, nas dependências do IFSC-Garopaba, tiveram um impacto bastante significativo no que concerne ao processo de leitura e escrita, a partir do desenvolvimento de uma prática pedagógica diferenciada, por exemplo, a proposta de produção de fanzines, que acabou por favorecer o potencial criativo dos alunos que, na maioria das vezes, acaba sendo bloqueado pelas práticas escolares. Para uma maior visibilidade, podemos observar, aseguir, o entrelaçamento entre as propostas de ensino, pesquisa e extensão desenvolvidas na experiência aqui descrita.

11 Resolução CONSUP/IFSC № 61, de doze de dezembro de 2016, que regulamenta as atividades de extensão, em seu capítulo III, define os diferentes tipos de atividades extensionistas. São elas: programa, projeto, curso, evento e produto. As ações descritas neste trabalho se enquadram na categoria "evento", pois, de acordo com a resolução "[...] é a atividade de extensão menos complexa, pontual, que preferencialmente deve estar contida em planejamento de atividades maiores como o projeto, visando promover e divulgar mutuamente conhecimentos produzidos no processo de aprendizagem, com a atuação de discentes e servidores e a participação da comunidade externa, com carga horária máxima de 40 horas distribuídas em até sete dias consecutivos." 
Figura 3: As atividades com os Fanzines no tripé ensino, pesquisa e extensão
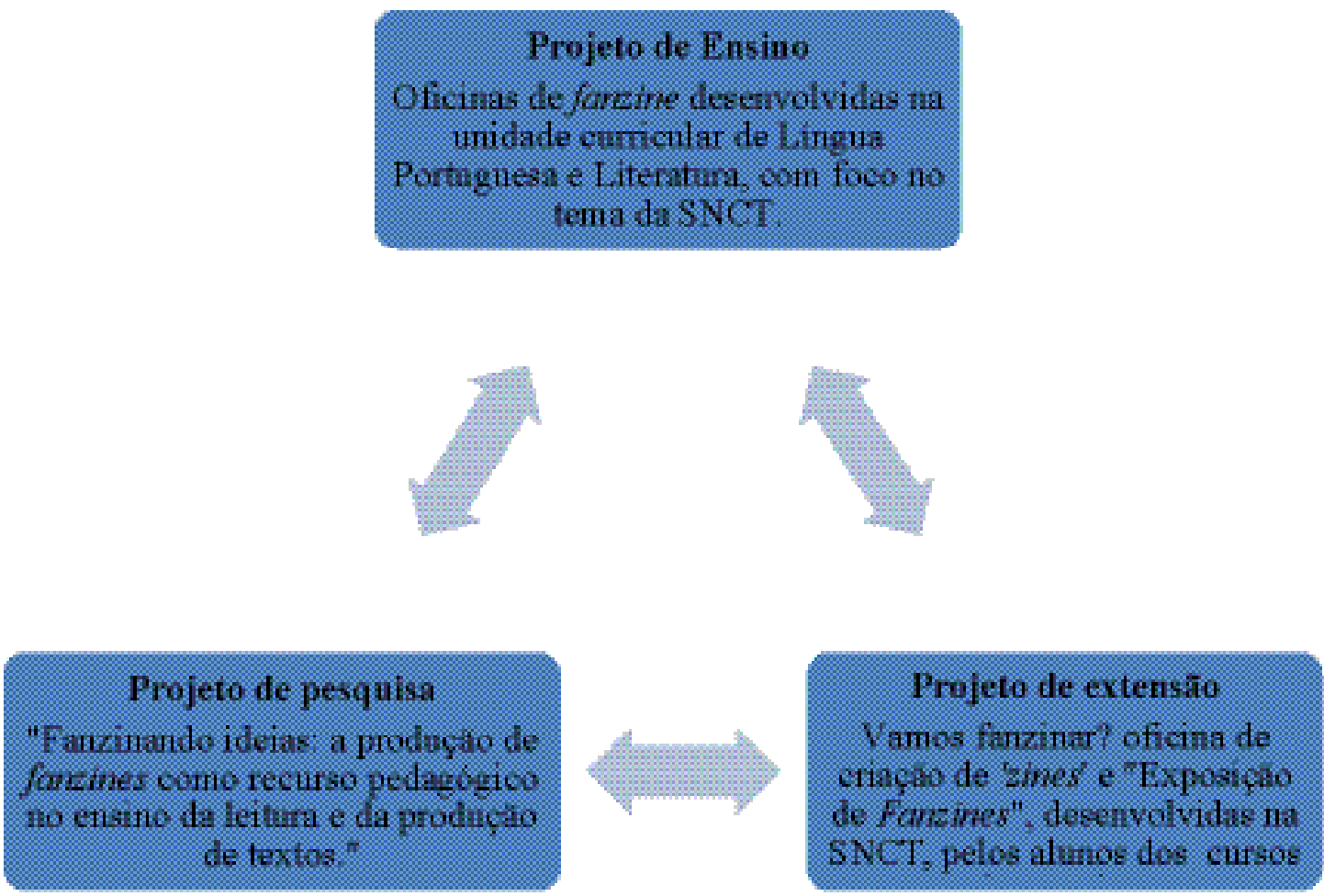

Fonte: Elaborado pelas autoras.

Quanto ao percurso de desenvolvimento das atividades, no decorrer do projeto de ensino, muitos estudantes relataram dificuldade em conseguir alcançar o objetivo final, porque, de acordo com eles, faltou-lhes criatividade, algo que foi sendo ressignificado ao longo do processo. Quando da realização da pesquisa, ao responderem à questão "Quais foram os aspectos positivos do desenvolvimento do projeto?", os que mais se destacaram dizem respeito à criatividade, como pode ser observado:

E3 $3^{12}: \mathrm{O}$ aprendizado de diferentes técnicas, o desenvolvimento da criatividade e também por ser algo mais dinâmico na aula;

E29: A elaboração de um tipo de arte por muitos desconhecida, a expressão de ideias e informações de forma criativa e a 'quebra' do padrão dos trabalhos escolares;

E36: O aprendizado sobre Bioeconomia, pois era o tema da Semana Nacional de Ciência e Tecnologia. Tive a oportunidade de trabalhar com os zines e gostei bastante disso. É um grande incentivo para a produção independente. (citação oral, obtida por meio de entrevista).

É importante observar o aspecto 'libertador' destacado pelos alunos no que concerne à ação de se colocarem como autores, responsáveis pela criação de algo que foge dos padrões não só comerciais, mas, principalmente, de trabalhos escolares. Esse rompimento causado por práticas pedagógicas que destoam e divergem de estruturas preestabelecidas de ensino-aprendizagem da língua materna permite-nos pensar, de acordo com Galvão (2010):

12 Os estudantes, cujos depoimentos são apresentados neste artigo, são representados pela letra $\mathrm{E}$, com referência ao termo estudante, acrescida de números, atribuídos de acordo com a ordenação dada aos questionários respondidos. 
[...] os fanzines como um campo de experimentação da língua e da linguagem, observando essas práticas que fabricam textos e imagens pelas junções, montagens e agrupando elementos incongruentes - produção de mundos através da linguagem bricolada. (GALVÃO, 2010, p. 94, grifos nossos).

No conjunto dos fanzines produzidos no projeto, além da criatividade posta, é notório o uso de outros diferentes gêneros textuais como: HQs, poemas, trechos de canções, charges, memes, gráficos, tabelas, sem mencionar as ilustrações, os recortes de imagens, fotografias, em um movimento que busca, incessantemente, o entrelaçamento entre textos e imagens, rompendo significações e estabelecendo novos sentidos.

Na questão: "O que você achou da proposta de produção de fanzines?", os alunos frisaram que:

E33: Para mim, foi muito interessante trabalhar um assunto [Bioeconomia] tão importante dessa forma. O fato de ser algo que rompe com os formatos tradicionais de trabalhos me chamou muito a atenção.

E35: Achei muito legal ter a possibilidade de conhecer fanzines. Acabei encontrando plataformas digitais com assuntos que gosto e acompanho até hoje.

E39: Muito interessante! Gostei de fazer algo com as minhas próprias mãos.

E43: Foi muito legal, pois conheci ofanzine e achei muito interessante. É uma maneira barata e fácil para novos autores.

E47: Foi uma proposta muito diferente e criativa, que sai do tradicional da sala de aula. (citação oral, obtida por meio de entrevista).

Destaca-se, ainda, que, do total de sessenta alunos participantes, $89 \%$ desconhecia o universo dos fanzines antes da aplicação do projeto. Um percentual significativo, equivalente a 78\%, frisou a importância do projeto para o desenvolvimento de conhecimentos relativos à temática da SNCT, no caso, sobre Bioeconomia. Ao serem questionados a respeito dos aspectos negativos no desenvolvimento da proposta, as respostas que mais apareceram foram:

E45: Foi difícil, pois na criação e desenvolvimento do zine é tudo muito preocupante, pela sensação do que o outro sentirá ao apreciar a obra.

E32: Por ser algo novo, pois foi a primeira vez que fizemos, o processo de produção foi um pouco estressante e demandou bastante tempo.

E40: Muito estresse em elaborar o fanzine, se algo não dava certo, eu e minha dupla fazíamos tudo de novo. (citação oral, obtida por meio de entrevista).

Muito embora as declarações dos estudantes listadas anteriormente tenham sido classificadas por eles como aspectos negativos da produção, podemos perceber que, ao serem estimulados à produção, assumiram os efetivos compromissos de autoria daquilo que produziram. Isso pode ser percebido quando afirmam da preocupação "[...] do que o outro sentirá quando apreciar a obra" (E45); "[...] se algo não dava certo, eu e minha dupla fazíamos tudo de novo" (E40). Com isso, consideramos que o propósito de utilização dos fanzines como gênero textual, atrelado ao projeto de extensão, levando os textos à comunidade, permitiram que os estudantes efetivamente se colocassem na condição de autores. É como afirma Giraldi (2010, p. 136 apud SILVEIRA; CASSIANI; LINSINGEN, 2018, p. 15): “[...] para a assunção da autoria, é preciso que os processos de ensino/ aprendizagem escolar permitam a abertura de um espaço de dizer".

Já na questão "Você acredita que o fanzine contribuiu para aprendizagem da leitura e da escrita? Por quê?", as respostas mais significativas foram: 
E37: Sim, pois é uma maneira diferenciada de mostrar isso ao público, servindo de incentivo para o conhecimento. Ainda mais se levarmos em conta as possibilidades de apresentar os conteúdos, sejam eles didáticos ou não.

E39: Contribuiu sim, de forma que quando formos escrever algo, poderemos "sair da caixa" e utilizar a criatividade.

E53: Sim, pois tivemos que ler e formular textos para que o fanzine tivesse um conteúdo de qualidade.

E26: Sim, por ter que pesquisar o assunto [Bioeconomia]. E também pelo fato de ser lido por outras pessoas, então não poderia ter erros de escrita.

E15: Sim, com certeza, pois com o fanzine deu para explorarmos várias formas de escrita e, com isso, praticamos a nossa leitura e interpretação. (citação oral, obtida por meio de entrevista).

Pela análise das respostas, é possível afirmar que a produção de fanzines se revelou como uma excelente possibilidade para o exercício não só da criatividade, como também para o desenvolvimento da autoria, colaborando, assim, para a desconstrução de discursos como "não sou capaz de escrever" ou, ainda "não gosto de escrever". Para fazer a autonomia aflorar nos jovens estudantes do ensino médio, faz-se necessário "[..] promover uma prática de ensino de língua materna menos artificial e instrumental, que contemple a necessidade de jovens que já produzem textos em gêneros diversos" (BUNZEN, 2012, p. 159). No entanto, para alcançar esse processo, nós, professores, precisamos "[...] pensar em aulas e materiais didáticos para esse nível de ensino que estabeleçam uma inter-relação entre as atividades de leitura, produção de texto e análise linguística e que não fragmentem a relação entre a língua e a vida" (BUNZEN, 2012, p. 159).

\section{Um esboço de conclusão...}

Os resultados obtidos com a produção dos fanzines são bastante ilustrativos desse processo que busca formar leitores e escritores autônomos e críticos. Em consonância com o exposto, vale destacar as reflexões de Fernanda Meirelles (2008), em sua pesquisa de pós-graduação, quando enfatiza o fato de que, no caso do uso do fanzine na escola, não se trata apenas de "fazer um jornalzinho", cortando e colando, mas sim observar o que este fazer provocará em termos de pensamento crítico e o quanto isto vai significar para a prática do aluno e do professor, somando possibilidades de se (re)pensar o aprendizado.

Nota-se, portanto, que os resultados obtidos com as atividades de ensino, pesquisa e extensão articuladas com o ensino de leitura e produção de textos permitiram não só contribuir para com a análise dos efeitos de práticas diferenciadas para o ensino, como também possibilita a abertura de espaços profícuos para o desenvolvimento da leitura e da escrita de jovens vinculados ao Ensino Médio, promovendo uma reflexão em relação ao processo de ensino-aprendizagem dos estudantes.

A experiência aqui descrita iniciou com um projeto de ensino, levando à sala de aula um gênero textual pouco usual nesse contexto. Os estudantes, com a estratégia, foram levados a produzir textos com diferentes suportes e recursos, indo da escrita no papel à máquina de escrever e ao computador, passando pelo emprego de técnicas que dão ao texto novos formatos (como ilustrado nas figuras 1 e 2). Para além disso, eles foram instigados à produção escrita com um público em específico, já que participaram de projetos de extensão e comercializaram (eis o público leitor!) os materiais na Semana Nacional de Ciência e Tecnologia.

Nesse cenário de articulação entre ensino, pesquisa e extensão, os dados da pesquisa desenvolvida junto aos alunos vieram a reforçar aquilo que é o marco com o qual esta experiência visa a contribuir: evidenciar que a utilização de diferentes gêneros textuais, sobretudo aqueles que 
colocam o aluno na condição de protagonista, contribui para a efetiva formação linguística dos sujeitos que passam pela escola.

\section{Referências}

BRASIL. Parâmetros Curriculares Nacionais (PCNs). Orientações educacionais complementares aos parâmetros curriculares nacionais: Linguagens, Códigos e suas Tecnologias. Brasília, DF: MEC, 2006.

BUNZEN, Clecio. Da era da composição à era dos gêneros: o ensino de produção de texto no ensino médio. In: BUNZEN, Clecio; MENDONÇA, Márcia. (org.). Português no ensino médio e formação do professor. São Paulo: Parábola Editorial, 2006.

CECCANTINI, João Luís. Leitores iniciantes e comportamento perene de leitura. In: SANT'ANNA, Affonso Romano de. Mediação de Leitura - Discussões e alternativas para a formação de leitores. São Paulo: Global, 2009.

CECCANTINI, João Luís. Mentira que parece verdade: os jovens não leem e não gostam de ler. In: FAILLA, Zoara (org.). Retratos da leitura no Brasil 4. Rio de Janeiro: Sextante, 2016.

FAILLA, Zoara (org.). Retratos da leitura no Brasil 4. Rio de Janeiro: Sextante, 2016.

GALVÃO, Demetrios Gomes. Ressonâncias no meio do caminho e/ou no caminho do meio: a poética infame dos fanzines. In: Muniz, Celina R. (org.). Fanzines: autoria, subjetividade e invenção de si. Fortaleza: Edições UFC, 2010. p. 81-97.

IFSC. Plano de Desenvolvimento Institucional. Capítulo 2: Projeto Pedagógico Institucional. Florianópolis: IFSC, 2015. Disponível em: https://pdi.ifsc.edu.br/files/2015/07/Capitulo02_revisado.pdf. Acesso em: 05 maio 2020.

KLEIMAN, Ângela. Oficina de Leitura: teoria e prática. Campinas: Pontes: IEC, 1993.

KOCH, Ingedore. Ler e compreender os sentidos do texto. São Paulo: Contexto, 2012.

MAGALHÃES, Henrique. O que é fanzine. São Paulo: Brasiliense, 1993.

MARANHÃO, Renata Queiroz. Fanzines nas escolas: convite à experimentação. Ceará: EdUECE, 2012.

MARCUSCHI, Antônio. Produção textual, análise de gêneros e compreensão. São Paulo: Parábola Editorial, 2010.

MEIRELES, F. Zines. Yoyô: uma experiência instintiva em arte-educação. 2008. Trabalho de Conclusão de Curso (Especialização em Arte-Educação) - Instituto Federal de Educação, Ciência e Tecnologia do Ceará - CEFET, Fortaleza, 2008.

NETO, Elydio; ANDRAUS, Gazy. Dos zines aos biograficzines: compartilhar narrativas de vida e formação com imagens, criatividade e autoria. In: MUNIZ, Celina (org.). Fanzines: autoria, subjetividade e invenção de si. Fortaleza: Edições UFC, 2010.

SILVEIRA, José Carlos da; CASSIANI, Suzani; LINSINGEN, Irlan Von. Escrita e autoria em texto de iniciação científica no ensino fundamental: uma outra relação com o saber é possível? Ciênc. Educ., Bauru, v. 24, n. 1, p. 9-25, 2018. Disponível em: https://www.scielo.br/pdf/ciedu/v24n1/1516-7313-ciedu-24-01-0009.pdf. Acesso em: 06 ago. 2020.

ZAVAM, Aurea Suely. Fanzine: a plurivalência paratópica. Linguagem em (Dis)curso - LemD, Tubarão, v. 6, n. 1, p. 9-28, jan./abr. 2006. Disponível em: http://linguagem.unisul.br/paginas/ensino/pos/linguagem/linguagem-em-discurso/0601/060101.pdf . Acesso em: 05 ago. 2020.

ZILBERMAN, Regina (org.). Leitura em crise na escola: as alternativas do professor. 11. ed. Porto Alegre: Mercado Aberto, 1993.

ZILBERMAN, Regina. A leitura e o ensino da literatura. Curitiba: InterSaberes, 2012.

Data de submissão: 11/11/2020

Data de aceite: $15 / 12 / 2020$ 